[original idea]

Diamond Open Access

\title{
Self-Publishing Journal
}

Open Collaboration*广

September 18, 2020

\begin{abstract}
We propose a disruption between the publication of scientific articles and the quality control agency by the development of Self-Publication Journals.
\end{abstract}

keywords: open science, open access, self-publication, publishing system, scientific journal

The most updated version of this paper is available at https://osf.io/782da/download

\section{Introduction}

1. By Self-Publication Journal (SPJ), we mean a scientific journal in which the author and the editor are the same person.

2. Papers are precious pieces of knowledge and empowerment.

3. Researchers produce papers.

4. Paywall journals forbid the free open access to the knowledge produced by the scientists [1].

*All authors with their affiliations appear at the end of this paper.

†Corresponding author: mplobo@uft.edu.br| Join the Open Collaboration 
5. There is an urgent need to upgrade the publishing system such that it fully incorporates the potentialities of the digital technology $[2,3]$.

6. Unfortunately, traditional journals do not meet all the technological demand of the academic publishing.

7. In summary, since papers are precious pieces of knowledge produced by researchers, since paywall journals lock the scientific knowledge, and due to (5) and (6), then it is pretty logical to conclude that the best option left to the researchers is to Reinvent Scientific Journals [4].

8. The idea for the SPJ is similar to the self-publication of books.

\section{Proposition}

9. Each and every researcher can build and run her/his own self-publishing scientific journal.

\section{Do-it-yourself}

10. The Overlay Journal is a modern and robust alternative model for the publishing system of scientific knowledge $[5,6]$.

11. One can check the guidelines to create a journal in "A do-it-yourself overlay journal" [7].

\section{Post-publication review}

12. In this paper, we take for granted that publication is independent of peer review.

13. Review can happen post publication. 


\section{Open invitation and huge collaboration}

14. The author can issue an open invitation calling for new collaborators to co-author any paper published in a post-publication review journal.

15. Huge collaboration increases the quality of the papers being produced.

16. Reviewers can also be invited to co-author the papers under review [8].

\section{Quality}

17. A Quality Standards Committee Agency (QCA) would rank the SPJs [9].

\section{Flexibility}

18. The papers can be written in any format that is more convenient to both the reader and the author.

19. Microarticles are short versions of scientific articles written in enumerated items to foster transparency and to help communication $[10,11]$.

\section{Disruption}

20. Traditional journals intertwine two operations:

(i) publishing;

(ii) asserting the quality control.

21. We propose a disruption between the publishing institution and the quality control agency.

22. In other words, (21) means that the journal is no longer both the publisher and the quality control agency. 
23. The authors publish what they believe are high-quality papers in their own SPJs.

24. The quality control agencies assert the quality of the papers and the quality of the SPJs as well.

\section{How to convince researchers to self-publish their work?}

25. We envisage that the following guidelines would strengthen the SPJ system of academic publishing.

26. Create your own overlay journal [7].

27. Publish high-quality papers in your SPJ [9].

28. (27) would show to the scientific community that "what" is published is more important then "where" it is published.

29. The self-publication system is one alternative solution that fits perfectly those researchers that have sufficient freedom to publish their results anywhere.

30. In Brazil, there are researchers employed in universities that offer stability in their jobs.

31. Use (27) to convince funders and stakeholders that SPJ is a trustworthy system of academic publishing.

32. Usually it is our peers who decide which research will be funded.

33. By convincing our peers that SPJ produces high-quality papers, SPJ can be consolidated as a legitimate mean of producing scientific knowledge. 


\section{Further Reading}

34. Promoting an open research culture [12]

http://doi.org/10.1126/science.aab2374

35. Reinventing Scientific Journals [4] https://doi.org/10.31219/osf.io/kzfmn

36. Collaborative Open Access Journals [13] https://doi.org/10.31219/osf.io/4wcvr

37. Peer Reviewer $=$ Co-Author (in the OJMP) $[8]$ https://doi.org/10.31219/osf.io/xv6kb

38. Universal Scientific Database [14] https://doi.org/10.31219/osf.io/4whbp

39. Scientific Tags [15] https://doi.org/10.31219/osf.io/tahx5

40. Open Knowledge Base: Resources and Units of Knowledge [16] https://doi.org/10.31219/osf.io/7vayt

41. Open Mathematics Knowledge Base [17] https://doi.org/10.31219/osf.io/evq8a

42. 'Is there a connection between quantity and quality' in a scientific article? [18] https://doi.org/10.31219/osf.io/kfwxd

\section{Final Remarks}

43. Self-Publishing Journals (SPJs) offer much faster means and it gives more flexibility for the researchers to publish their ideas and results.

44. Quality control agencies can verify and rank the SPJs. 


\section{Open Invitation}

Review, add content, and co-author this paper $[10,19]$.

Join the Open Collaboration (https://bit.ly/ojmp-slack).

Send your contribution to mplobo@uft.edu.br.

\section{Open Science}

The latex file for this paper together with other supplementary files are available [20].

\section{Ethical conduct of research}

This original work was pre-registered under the OSF Preprints [21], please cite it accordingly [22]. This will ensure that researches are conducted with integrity and intellectual honesty at all times and by all means.

\section{Acknowledgement}

Do we still need journals?

https://gitlab.com/publishing-reform/discussion/-/issues/59

\section{References}

[1] Paywall: The Business of Scholarship. https://paywallthemovie.com

[2] Nielsen, Michael. Reinventing discovery: the new era of networked science. Vol. 70. Princeton University Press, 2020.

[3] Hendler, James. "Reinventing academic publishing, part 2." IEEE Intelligent Systems 22.6 (2007): 2-3. 
[4] Lobo, Matheus P. "Reinventing Scientific Journals." OSF Preprints, 8 June 2020. https://doi.org/10.31219/osf.io/kzfmn

[5] Van Noorden, Richard. Mathematicians aim to take publishers out of publishing. Nature News, 2013. https://www.nature.com/news/mathematicians-aim-to-takepublishers-out-of-publishing-1.12243

[6] Ball, Philip. "Leading mathematician launches arXiv 'overlay' journal." Nature News 526.7571 (2015): 146. https://www.nature.com/news/leading-mathematician-launchesarxiv-overlay-journal-1.18351

[7] Lobo, Matheus P. "A Do-it-yourself Overlay Journal." OSF Preprints, 27 June 2019. https://doi.org/10.31219/osf.io/gy8qv

[8] Lobo, Matheus P. "Peer Reviewer = Co-author (in the OJMP)." OSF Preprints, 17 Nov. 2019. https://doi.org/10.31219/osf.io/xv6kb

[9] Lobo, Matheus P. "Darwinian Natural Selection of Articles in Overlay Journals." OSF Preprints, 29 June 2019. https://doi.org/10.31219/osf.io/z8e3m

[10] Lobo, Matheus P. "Microarticles." OSF Preprints, 28 Oct. 2019. https://doi.org/10.31219/osf.io/ejrct

[11] Lobo, Matheus P. "An Open Essay on Open Science." OSF Preprints, 15 Apr. 2019. https://doi.org/10.31219/osf.io/42jsg

[12] Nosek, Brian A., et al. "Promoting an open research culture." Science $348.6242 \quad$ (2015): 1422-1425. https://www.ncbi.nlm.nih.gov/pmc/articles/PMC4550299

[13] Lobo, Matheus P. "Collaborative Open Access Journals." OSF Preprints, 13 Feb. 2020. https://doi.org/10.31219/osf.io/4wcvr 
[14] Lobo, Matheus P. "Universal Scientific Database." OSF Preprints, 27 Apr. 2019. https://doi.org/10.31219/osf.io/4whbp

[15] Lobo, Matheus P. "Scientific Tags." OSF Preprints, 6 May 2020. https://doi.org/10.31219/osf.io/tahx5

[16] Lobo, Matheus P. "Open Knowledge Base from Resources and Units of Knowledge." OSF Preprints, 17 May 2020. https://doi.org/10.31219/osf.io/7vayt

[17] Lobo, Matheus P. "Open Mathematics Knowledge Base." OSF Preprints, 13 May 2020. https://doi.org/10.31219/osf.io/evq8a

[18] Lobo, Matheus P. "is There a Connection Between Quantity and Quality' in a Scientific Article?." OSF Preprints, 30 May 2019. https://doi.org/10.31219/osf.io/kfwxd

[19] Lobo, Matheus P. "Simple Guidelines for Authors: Open Journal of Mathematics and Physics." OSF Preprints, 15 Nov. 2019. https://doi.org/10.31219/osf.io/fk836

[20] Lobo, Matheus P. "Open Journal of Mathematics and Physics (OJMP)." OSF, 21 Apr. 2020. https://doi.org/10.17605/osf.io/6hzyp

[21] COS. Open Science Framework. https://osf.io

[22] Lobo, Matheus P. "Self-publishing Journal." OSF Preprints, 17 June 2020. https://doi.org/10.31219/osf.io/782da

\section{The Open Collaboration}

Matheus Pereira Lobo (lead author,mplobo@uft.edu.br) $)^{1,2}$

https://orcid.org/0000-0003-4554-1372

${ }^{1}$ Federal University of Tocantins (Brazil)

${ }^{2}$ Universidade Aberta (UAb, Portugal) 